\title{
NILAI-NILAI PENDIDIKAN ISLAM DALAM HADIS-HADIS AKIKAH
}

\author{
Nurul Azizah \\ Universitas Wahid Hasyim Semarang \\ qnaazizatyi@yahoo.co.id
}

\begin{abstract}
Abstrac
Akikah is a form of parental love and the provision of the first education for children. The marriage practiced by the Jahiliyah in ancient times was replaced by the Prophet with the practices of Islamic marriage and contained educational value in it. This study focused on the akikah traditions contained in the book of hadith mu'tabar. This research is a qualitative research in the form of a research library that collects data from relevant books. The purpose of this study is to find out the akikah rituals contained in the hadith of marriage, and to know the value of Islamic education contained in it.This research shows that the akikah hadith narrated by Abi Buraidah, Ali, Samurah, and 'Aisyah contain several rituals, including: cutting a child's hair, smearing his hair with za'faran oil, alms as heavy as hair that has been cut, named, tahnik, and akikah. From this practice, akikah contains values of Islamic education, including: faith education, moral education, health education, social education, psychology education, and beauty education.
\end{abstract}

Key Word: Islamic Education, Hadits Akikah

\begin{abstract}
Abstrak
Akikah merupakan bentuk kasih sayang orang tua dan pemberian pendidikan pertama bagi anak. Akikah yang dipraktekkan orang Jahiliyah pada zaman dahulu diganti oleh Rasulullah dengan praktik-praktik akikah islami dan mengandung nilai pendidikan di dalamnya. Penelitian ini difokuskan pada hadis-hadis akikah yang terdapat dalam kitab hadis mu'tabar. Penelitian ini merupakan penelitian kualitatif berupa library research yang mengumpulkan data-data dari buku-buku yang relevan. Tujuan penelitian ini untuk mengetahui ritual-ritual akikah yang terdapat dalam hadis akikah, serta untuk mengetahui nilai pendidikan Islam yang terdapat di dalamnya. Penelitian ini menunjukkan bahwa hadis akikah yang diriwayatkan oleh Abi Buraidah, Ali, Samurah, dan 'Aisyah mengandung beberapa ritual, di antaranya: memotong rambut anak, melumuri rambutnya dengan minyak za'faran, sedekah seberat rambut yang telah dipotong, diberi nama, tahnik, dan akikah. Dari praktik tersebut, akikah mengandung nilaiPROGRESS - Volume 7, No. 1, Juni 2019


nilai pendidikan Islam, di antaranya: pendidikan keimanan, pendidikan akhlak, pendidikan kesehatan, pendidikan sosial, pendidikan psikologi, dan pendidikan keindahan.

Kata Kunci: Pendidikan Islam, Hadis Akikah.

\section{A. PENDAHULUAN}

Akikah ${ }^{1}$ secara bahasa diambil dari kata " $a$ - 'aqq, as-syaqq = membelah, dan al-Qat'u = memutuskan" yang berarti memecah atau memotong. Pengertian ini merujuk pada peristiwa memotong rambut bayi yang baru lahir. Sebab, hewan akikah disembelih ketika bayi dicukur rambutnya. ${ }^{2}$ Akikah adalah hewan sembelihan untuk anak baru lahir. Akikah juga diartikan sebagai hewan yang disembelih untuk anak baru lahir pada hari ketujuh (seminggu). ${ }^{3}$

Syarah Bulugul Maram karya Abdul Qadir Syaibah menjelaskan bahwa akikah ialah kambing atau domba yang disembelih pada saat pencukuran rambut bayi pada hari ketujuh dari kelahirannya. Asal kata العَقُ (akikah) bermakna

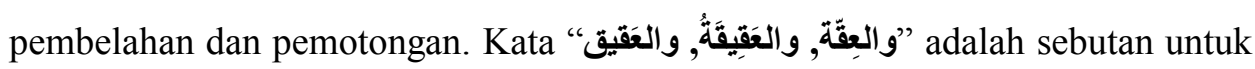
rambut setiap bayi yang lahir dari manusia atau hewan ternak. ${ }^{4}$

\footnotetext{
${ }^{1}$ Akikah pertama kali dipraktikkan oleh orang Jahiliyah. Ada tiga macam kebiasaan orang Arab Jahiliyah yang berkaitan dengan sembelihan hewan, yaitu: Akikah, Rajabiyah (Rajabiyah adalah penyembelihan seeor domba yang dilauan oleh orang-orang Arab Jahiliyyah pada bulan Rajab. Dagingnya emudian dimaan oleh anggota eluarga yag menyembelih, sementara sebagianya dimasa lantas diberikan kepada tetangga). (Lihat. Wahbah al-Zuhaili, Fiqih Islam wa Adillatuhu, terj. Abdul Hayyie al-Kattani dkk, (Jakarta: Gema Insani, 2011), hlm. 295.), dan 'Atirah (Atirah adalah sembelihan yang mereka sembelih pada sepuluh hari pertama bulan Rajab dan mereka menyebutnya Rajabiyah. (Lihat. Ibnu Hajar al-Asqalani, Talkhisul Habir, terj. Amir Hamzah dkk, (Jakarta: ustaka Azzam, 2012), hlm. 464). Orang Jahiliyah pada zaman dahulu selalu menyembelih hewan ketika anaknya lahir, mereka menyembelih seekor kambing, mencukur rambut, dan melumuri kepalanya dengan darah hewan yang disembelih. Kebiasaan melumuri darah ini, oleh syari'at Islam diganti dengan melumurkan air bunga.

${ }^{2}$ Musțafa Dib al-Buga, al-Tażib fi Adillati Matn al-Ghayah wa al-Taqrib, terj. Toto Edidarmo, (Jakarta: Mizan Publika, 2012), hlm. 652. hlm. 299.

${ }^{3}$ Sayyid Sabiq, Fiqh as-Sunah, terj. Noor Hasanuddin, (Jakarta: Darul Fath, 2004),

${ }^{4}$ Abdul Qadir Syaibah al-Hamd, Syarah Buluqul Maram, terj. Muhammad Iqbal dkk, (Jakarta: Darul Haq, 2014), hlm. 3.
} 
Dari pengertian di atas, akikah adalah penyembelihan hewan untuk anak baru lahir pada hari ketujuh dari kelahirannya. Penyembelihan tersebut diiringi dengan pemotongan atau pencukuran rambut anak. Akikah bisa berupa kambing maupun domba. Dalam prakteknya, akikah dilakukan sebagai ungkapan syukur orang tua dan slametan untuk anak yang baru lahir.

Akikah merupakan upacara keagamaan yang memasyarakat di kalangan umat Islam yang dalam prosesnya ada penyembelihan hewan. Sebagai bagian dari keyakinan hidup masyarakat Muslim, tentunya upacara akikah bukan sekedar diadakan, melainkan diyakini sebagai ajaran yang telah dicontohkan oleh Rasulullah Saw. ${ }^{5}$ Di dalam ritual akikah terdapat pula nilai-nilai pendidikan yang diberikan kedua orang tua kepada anaknya. Maka dari itu, Islam menganjurkan orang tua untuk mengakikahkan anaknya sebagai awal pemberian pendidikan kepadanya.

Akikah adalah salah satu manifestasi kasih sayang orang tua terhadap anaknya. Namun, anjuran agama ini nampaknya masih mendapatkan perhatian kurang serius sehingga belum semua orang tua Muslim mengakikahi anaknya. Hal demikian bisa jadi disebabkan, kurangnya perhatian dan pemahaman orang tua Muslim ihwal ajaran ibadah akikah. Maka dari itu, Islam menganjurkan orang tua untuk mengakikahkan anaknya sebagai awal pemberian pendidikan kepada anak.

Mengingat hal tersebut, maka menjadi sangat penting mempelajari serangkaian upacara ibadah akikah yang terdapat dalam hadis Nabi. Dan selanjutnya bisa dipraktekkan orang tua dalam mendidik anak di lingkungan keluarganya. Sehingga dengan demikian diharapkan nantinya anak tersebut akan menjadi generasi muslim yang tangguh, yang berbakti kepada orang tua, dan berguna bagi keluarga, agama, dan negaranya.

${ }^{5}$ Hasan Asy'ari Ulama'i, Aqiqah dengan Burung Pipit, (Semarang: Rasail Media Group, 2012), hlm. 2. 
Tradisi akikah yang dilakukan di beberapa daerah memiliki perbedaan, di antaranya yang dilakukan di Kel. Baamang Hulu. Pelaksanaa akikah sering dilakukan terpisah dengan pemberian nama anak, hal ini dikarenakan tingkat perekonomian masyarakat Kel. Baamang Hulu berbeda-beda. Adapun rangkaian didalam upacara akikah dan tasmiah yang dilaksanakan secara garis besar dimulai dengan penyembelihan hewan akikah, kemudian pemberian nama, tahnik, pemotongan sedikit rambut. ${ }^{6}$

Pelaksanaan akikah yang dilakukan oleh masyarakat Kudus tidak sekedar memberi nama dan menyembelih hewan akikah tetapi juga diiringi dengan mencukur sebagian rambutnya dan bersedekah seberat timbangan rambut yang telah dicukur tersebut, mengadakan tasyakuran dengan mengundang tetangga dekat dan sanak saudara, setelah adanya pemotongan hewan aqiqah, maka disunnahkan tulang pada hewan aqiqah tersebut tidak dipecah-pecah, agar tulang si bayi itu selamat. ${ }^{7}$

Melengkapi dan menguatkan penelitian sebelumnya, pada penelitian ini pelaksanaan akikah dikaitkan dengan perintah Rasulullah Saw, perihal pelaksanaan akikah dan dikaitkan pula dengan nilai-nilai pendidikan di dalamnya. Agar menjadi perhatian lebih bagi orang tua sebagai luapan kasih sayang terhadap anaknya.

Penelitian ini merupakan penelitian kepustakaan yang mengkaji tentang hadis aqiqah yang akan dihubungkan dengan nilai-nilai pendidikan Islam. Ditemukan dalam kamus hadis Mu'jam al-Mufahras li Alfadz al-Hadis al-

${ }^{6}$ Muhammad Fitrianor, "Nilai-Nilai Pendidikan Islam Dalam Pelaksanaan Akikah dan Tasmiah Di Kel.Baamang Hulu Kec.Baamang Kab.Kotim", Jurnal Studi Agama dan Masyarakat, Volume 11, Nomor 1, Juni 2015, hlm. 23-43.

${ }^{7}$ Nafilatul Ilmiyyah, "Pemahaman Dan Implementasi Hadits-Hadits Aqiqah Pada Masyarakat Desa Kauman Kota Kudus”, Skripsi, (UIN Walisongo: 2016), 43-45. 
Nabawi terdapat 15 versi hadis yang membahas aqiqah, ${ }^{8}$ tetapi dalam penelitian ini akan difokuskan pada 4 hadis aqiqah yang mencakup di dalamnya ritualritual terkait akikah.

\section{B. PEMBAHASAN}

\section{Nilai-Nilai Pendidikan Islam}

Pendidikan Islam merupakan pendidikan secara khas memiliki ciri Islami yang kajiannya lebih difokuskan pada pemberdayaan umat berdasarkan al-Qur'an dan al-hadis. Artinya, kajian pendidikan Islam bukan sekedar menyangkut aspek normatif ajaran Islam, tetapi terapannya juga dalam ragam materi, institusi, budaya, nilai, dan dampaknya terhadap pemberdayaan umat. ${ }^{9}$ Pendidikan Islam adalah proses bimbingan dari pendidik kepada anak didik yang mengarah pada perbaikan sikap dan mental, kemudian akan terwujud dalam amal perbuatan sehingga terbentuklah pribadi muslim yang baik. ${ }^{10}$

Dari pengertian di atas, dapat disimpulkan bahwa pendidikan Islam adalah rangkaian proses sistematis, terencana dan komprehensif dalam upaya mentransfer nilai-nilai kepada peserta didik. Hal tersebut dilakukan dengan mengembangkan potensi yang ada pada diri mereka sehingga mampu melaksanakan tugasnya di muka bumi dengan sebaik-baiknya sesuai dengan nilai-nilai Ilahiah yang didasarkan pada al-Qur'an dan al-hadis di semua dimensi kehidupan.

\section{Dasar Pendidikan Islam}

Dasar adalah landasan berpijak atau tegaknya sesuatu agar berdiri dengan kokoh. Dasar suatu bangunan yaitu fondamen yang 1962), hlm.389.

${ }^{8}$ A.J Wensinck, Mu'jam al-Mufahras li al-fadz Hadis an-Nabawy, (Madinah: Baril,

${ }^{9}$ Sri Minarti, Ilmu Pendidikan Islam, (Jakarta: AMZAH, 2013), hlm. 25-26.

3.

${ }^{10}$ Fatah Syukur, Sejarah Pendidikan Islam, (Semarang, Pustaka Rizki Putra, 2012), 
menjadi landasan agar bangunan tersebut berdiri tegak dan kokoh. ${ }^{11}$ Dasar pendidikan Islam yaitu landasan yang menjadi sumber dari segala kegiatan pendidikan Islam yang dilakukan. ${ }^{12}$

Dasar pendidikan Islam yaitu al-Qur'an dan al-hadis. Di atas kedua pilar inilah dibangun konsep dasar pendidikan Islam. ${ }^{13}$ Umar dalam bukunya "Ilmu Pendidikan Islam" menambahkan dengan empat hal, yakni kata-kata Sahabat (madzhab Shahabi), kemaslahatan umat/sosial (maslahah al-mursalah), tradisi atau kebiasaan masyarakat ('urf), dan hasil pemikiran para ahli dalam Islam (ijtihad). ${ }^{14}$

Landasan pokok Pendidikan Islam adalah al-Qur'an dan al-hadis yang dapat dikembangkan dengan ijtihad, al-maslahah mursalah, istihsan, dan qiyas.

a. Al-Qur'an

Al-Qur'an mengandung ajaran pokok yang dapat dikembangkan untuk keperluan seluruh aspek kehidupan melalui ijtihad. Di dalam al-Qur'an terdapat banyak ajaran yang berisi prinsip-prinsip berkenaan dengan kegiatan atau usaha pendidikan. Cerita itu menggariskan prinsi materi pendidikan yang terdiri dari masalah iman, akhlak, ibadah, sosial dan ilmu pengetahuan. ${ }^{15}$

b. Sunah

${ }^{11}$ Nur Uhbiyati, Ilmu Pendidikan Islam, (Bandung: Pustaka Setia, 1997), hlm. 24.

${ }^{12}$ Fihris, Ilmu Pendidikan Islam, (Semarang: CV. Karya Abadi Jaya, 2015), 47.

${ }^{13}$ Haidar Putra Daulay, Pemberdayaan Pendidikan Islam di Indonesia, (Jakarta: Rineka Cipta, 2009), hlm. 7.

${ }^{14}$ Bukhari Umar, Ilmu Pendidikan Islam, (Jakarta: AMZAH, 2010), hlm. 32. 19-21.

${ }^{15}$ Zakiyah Darajat dkk, Ilmu Pendidikan Islam, (Jakarta: Bumi Aksara, 2014), hlm. 
Sunah menurut para ahli hadis adalah segala sesuatu yang disandarkan kepada Nabi Muhammad Swt terdiri dari ucapan, perbuatan, ketetapan, sifat, fisik atau budi pekerti, dan biografi, baik pada masa sebelum kenabian atau sesudahnya.

c. Ijtihad

Ijtihad dalam pendidikan harus bersumber dari al-Qur'an dan al-hadis yang dikembangkan oleh akal. Ijtihad di bidang pendidikan sangatlah perlu karena ajaran Islam yang terdapat dalam al-Qur'an dan al-Sunah hanyalah bersifat pokok. ${ }^{16}$ Oleh karena itu, untuk mengembangkan pendidikan Islam yang sesuai dengan perkembangan zaman, diperlukanlah ijtihad.

d. Mashlahah al-Mursalah

Para ahli pendidikan memiliki wewenang untuk menentukan undang-undang atau peraturan pendidikan Islam sesuai dengan kondisi lingkungan di mana ia tinggal.

e. 'Uruf

Kesepakatan bersama dapat dijadikan acuan dalam pelaksananaan pendidikan Islam. Syarat yang perlu diperhatikan di antaranya: 1) tidak bertentangan dengan nash, baik al-Qur'an maupun al-hadis, 2) tradisi yang berlaku tidak bertentangan dengan akal sehat dan tabi'at kesejahteraan masyarakat serta tidak mengakibatkan keruskan. ${ }^{17}$

\section{Pengertian dan Macam-macam Nilai-Nilai Pendidikan Islam}

Nilai-nilai pendidikan Islam adalah potensi yang dimiliki individu baik jasmani maupun rohani (fisik, psikis, akal, spiritual,

${ }^{16}$ Zakiyah Darajat dkk, Ilmu Pendidikan Islam, hlm. 21-22.

${ }^{17}$ Abdul Mujib dan Jusuf Mudzakkir, Ilmu Pendidikan Islam, (Jakarta: Kencana Prenada, 2006), hlm. 42. 
fitrah, talenta dan sosial) yang ditumbuhkembangkan melalui pendidikan dan bersifat abstrak.

Ruang lingkup nilai-nilai pendidikan Islam menurut Abdullah Nasikh Ulwan terdiri dari tujuh unsur yaitu: pendidikan keimanan, pendidikan moral, pendidikan fisik/jasmani, pendidikan rasio/akal, pendidikan kejiwaan, pendidikan seksual, pendidikan sosial.

a. Pendidikan Keimanan.

Adapun yang dimaksud dengan pendidikan keimanan adalah sinergi berbagai unsur aktifitas pedagogis, di antaranya: pengaitan anak dengan dasar-dasar keimanan, pengakraban dengan rukun Islam, dan pembelajaran tentang prinsip-prinsip syariat Islam. ${ }^{18}$

b. Pendidikan Moral.

Materi pendidikan moral merupakan latihan membangkitkan nafsu-nafsu rubbubiyah (ketuhanan) dan meredam/menghilangkan nafsu-nafsu syaithaniyah. Setelah materi-materi tersebut disampaikan kepada peserta didik diharapkan memiliki perilakuperilaku akhlak yang mulia dan menjauhi/meninggalkan perilakuperilaku akhlak yang tercela. ${ }^{19}$

c. Pendidikan Fisik/Jasmani.

Pendidikan jasmani atau pendidikan fisik berhubungan dengan tubuh atau fisiknya, adalah bentuk aktifitas yang dilakukan seseorang (atau orang yang menjaganya) dengan gerakan tubuh yang teratur dengan tujuan meningkatkan berbagai kemampuan

${ }^{18}$ Hanan Ațiyah Aț-Ṭuri, Mendidik Anak Perempuan di Masa Kanak-Kanak,(AdDaur At-Tarbawy Li Al-Walidain fi Tansyi'ah Al-Fatah Al-Muslimah fi Marhalah AtTufulah), terj. Aan Wahyudin, (Jakarta: Amzah, 2007), hlm. 1

${ }^{19}$ Heri Jauhari Mukhtar, Fiqh Pendidikan, (Bandung: PT Remaja Rosdakarya, 2005), hlm. 16. 
tubuh yang bermacam-macam dan menambah kecekatan gerakannya. $^{20}$

d. Pendidikan Rasio/Akal.

Pendidikan rasio/akal menekankan kepada perkembangan intelegensi manusia, diharapkan agar para pelajar dapat berfikir secara kreatif, inovatif, dan spekulatif berdasarkan ajaran Islam. ${ }^{21}$

e. Pendidikan Kejiwaan.

Pada materi ini peserta didik dilatih agar dapat membina hati nuraninya sehingga menjadi "tuan" dalam dirinya sendiri dan dapat menyerukan kebenaran dalam keadaan apapun.

f. Pendidikan Seksual.

Pendidikan seksual yang dimaksud di sini adalah bercorak Islami dan sesuai dengan perkembangan usia serta mental peserta didik. ${ }^{22}$ Contoh pendidikan seksual dalam Islam yakni dengan memisahkan tempat tidur anak dari kamar orang tua.

g. Pendidikan sosial.

Pendidikan sosial adalah proses pembinaan kesadaran sosial, sikap sosial, dan ketrampilan sosial agar anak bisa hidup dengan baik di tengah-tengah masyarakat. ${ }^{23}$

Nilai-nilai pendidikan Islam sesungguhnya terkait erat dengan nilai-nilai yang terdapat dalam Islam itu sendiri sehingga ruang

\footnotetext{
${ }^{20}$ Hanan Ațiyah Aț-Ṭuri, Mendidik Anak Perempuan di Masa Kanak-Kanak,(AdDaur At-Tarbawy Li Al-Walidain fi Tansyi'ah Al-Fatah Al-Muslimah fi Marhalah AtTufulah), terj. Aan Wahyudin, hlm. 53

${ }^{21}$ Arief, Armai, Pengantar Ilmu dan Metodologi Pendidikan Islam, (Jakarta: Ciputat Pers, 2002), hlm. 71.

${ }^{22}$ Heri Jauhari Mukhtar, Fiqh Pendidikan, hlm. 18.

${ }^{23}$ Bukhari Umar, Hadis Tarbawi Pendidikan dalam Perspektif Hadis, (Jakarta: Amzah, 2012), hlm. 55.
} 
lingkup pendidikan Islam bisa dikembangkan lagi sesuai asas-asas yang terdapat dalam ajaran Islam.

\section{A. Rangkaian Pelaksanaan Akikah dalam Hadis}

\section{Hadis Akikah}

a. Hadis riwayat Abi Buraidah R.a.

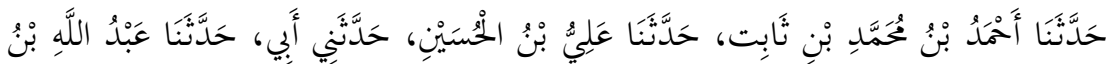

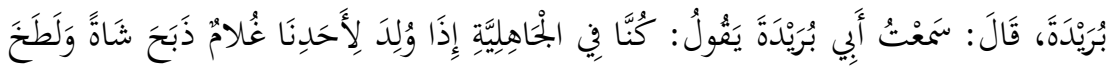

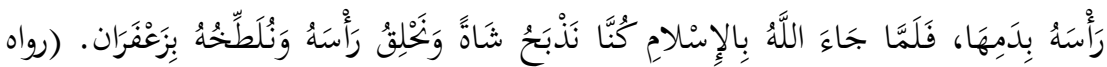
أبو داوود) 24

Telah diceritakan Aḥmad bin Muhammad bin Ṡābit, telah diceritakan 'Ali bin Husain, menceritakan padaku bapakku, dari 'Abdullah bin Buraidah, ia berkata: Saya mendengar Abi Buraidah berkata: "Bahwa pada saat kami di masa jahiliyah, bila salah seorang diantara kami mendapatkan (melahirkan) seorang bayi laki-laki, disembelihkanlah satu ekor kambing dan melumuri kepala si bayi dengan darah sembelihan tersebut, kemudian sejak Allah menghadirkan ajaran Islam, kami menyembelih kambing tersebut dan memotong rambut kepala si bayi serta kami bubuhi bayi tersebut dengan kunyit (za'faran) atau sejenis safran (tanaman)". (H.R Abū Dāwud).

\section{b. Hadis riwayat Ali Ra.}

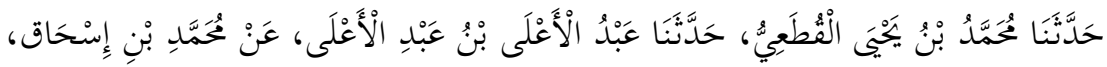

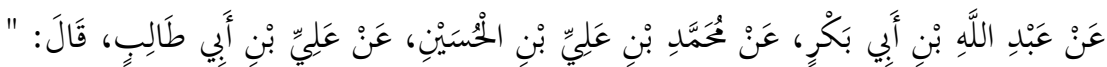

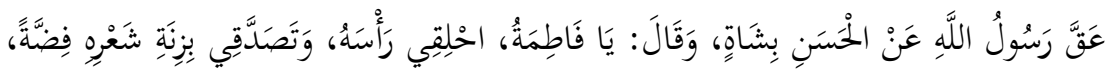

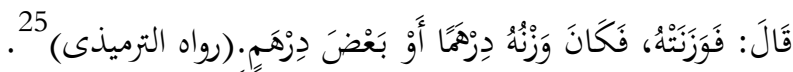

${ }^{24}$ Sulaiman, Abi Daud, Sunan Abi Dawūd, (Beirut: Darul Kitab al-'Ilmiah, 1996), 1240.

${ }^{25}$ al-Hauti, Kamal Yusuf, Al-Jami al-Sahih Sunan Al-Turmudzi) Juz IV, Beirut: Dar al-Kutub al-Ilmiah, t.t. hlm. 84. 
Telah menceritakan Muḥammad bin Yahya al-kuțo'iyyu, telah menceritakan 'Abdul A'ala bin 'Abdi al-A'ala dari Muhammad bin Ishaq dari Abdullah bin Abi Bakar dari Muhamad bin 'Ali bin Husain dari "Ali bin Abi Talib berkata: Rasulullah SAW., mengakikahkan Hasan dan Husain dengan satu ekor kambing, kemudian ia berkata: "Wahai Fatimah, potonglah rambutnya (si bayi) dan bersedekahlah sebuah perak seberat takaran rambut tersebut". (H.R al-Tirmīżi).

c. Hadis riwayat Samurah bin Jundab Ra.

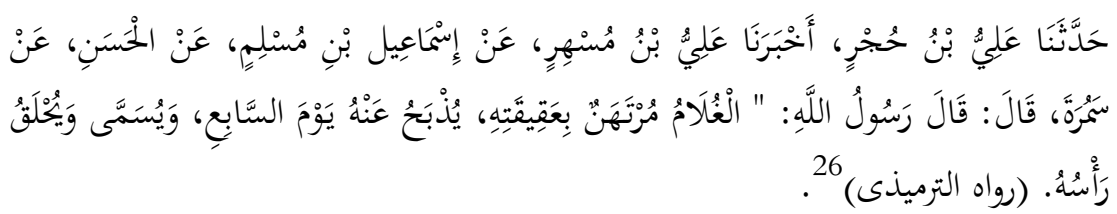

'Ali bin Hujr menceritakan kepada kami, 'Ali bin Mushir mengabarkan kepada kami dari Ismā’il bin Muslim, dari al-Ḥasan dari Samurah, ia berkata, Rasulullah SAW bersabda: "Seorang anak tergadai dengan akikahnya, yang disembelih atas namanya pada hari ke tujuh dari hari kelahirannya, diberi nama dan dicukur rambut kepalanya". (H.R al-Tirmīzii).

\section{d. Hadis riwayat 'Aisyah Ra.}

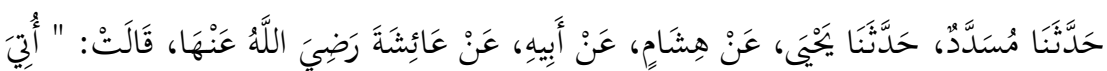

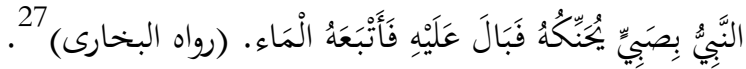

Diceritakan oleh Musaddad, diceritakan oleh Yahyya dari Hisyām dari bapaknya dari 'Āisyah Ra. Dia berkata: Aku membawa seorang bayi kepada Rasulullah SAW., untuk ditahnik (pemberian makanan secara simbolis oleh Nabi Saw., melalui olesan buah pada tenggorokan bayi), pada saat itu bayi tersebut mengompoli Nabi Saw., kemudian beliau menyiram ompol tersebut dengan air. (H.R al-Bukhārī).

${ }^{26}$ Kamal Yusuf al-Hauti, Al-Jami al-Sahih (Sunan Al-Turmuzii) Juz IV, hlm. 85).

${ }^{27}$ Imam Abi Abdillah bin Ismail bin Ibrahim Ibn Mugirah al-Bukhari al-Ju'fi, Shahih al-Bukhari Juz V, hlm. 216. 


\section{Rangkaian Pelaksanaan Akikah dalam Hadis}

\section{a. Memberikan nama anak (tasmiyah)}

Nama adalah doa dari orang tua kepada anaknya. Dianjurka bagi orang tua memberikan nama yang baik sebagai doa yang baik pula. Seperti nama-nama Islami yang diajarkan oleh Rasulullah SAW. Saat memberi nama pada anak, orang tua harus memilih nama yang paling indah dan mulia baginya. Orang tua dianjurkan menghindari nama yang buruk dan dapat menghilagkan kemuliaan anak atau bahkan akan menjadi bahan ejekan. Diperintahkan juga menjauhi nama-nama yang menjadi kekhususan Allah. Seperti A had (yang Esa), Khaliq (Sang Pencipta). ${ }^{28}$

Berdasarkan hadis yang diriwayatkan oleh Samurah, pemberian nama dilaksanakan pada hari ketujuh. Tetapi ada pendapat yang menyatakan bahwa pemberian nama dilaksanakan pada saat kelahiran langsung tanpa harus menunggu hari ketujuh. ${ }^{29}$ Dari kedua pendapat tersebut dapat disimpulkan bahwa waktu pemberian nama tidak terbatas pada hari ketujuh kelahiran. Tetapi yang sering terjadi di masyarakat, pemberian nama diberikan tidak lama dari waktu anak dilahirkan. Hal tersebut biasanya dilakukan antara hari pertama sampai ketujuh dari kelahiran anak, sekaligus mengadakan selametan atas kelahirannya.

${ }^{28}$ Abdullah Nasikh Ulwan, Tarbiyatul Aulad fil Islam terj. Arif Rahman Hakim, (Solo: Insan Kamil, 2016), hlm. 48-50. 46.

${ }^{29}$ Abdullah Nasikh Ulwan, Tarbiyatul Aulad fil Islam terj. Arif Rahman Hakim, hlm. 


\section{b. Memberikan makan yang dikenal dengan tahnik}

Salah satu amalan yang disyari' atkan Islam untuk anak baru lahir adalah mengunyahkan makanan (tahnik) ${ }^{30}$. Diutamakan orang yang mentahnik bayi tersebut adalah orang yang memiliki ketaqwaan dan keshalihan kuat. Agar dapat dijadikan pengantar keberkahan dan harapan supaya kelak anak tersebut juga memiliki ketaqwaan kuat. ${ }^{31}$

\section{c. Memotong rambut anak}

Terdapat perbedaan pendapat antara memotong sebagian saja ataukah mencukur. Tidak dipermasalahkan oleh para ulama' antara kedua perbedaan pendapat tersebut. Artinya, boleh memilih antara memotong ataupun mencukur, tetapi lebih baik mencukur rambut anak. Dengan dicukur, kotoran menempel yag dibawa saat lahir dapat hilang keseluruhan, dan dengan mencukur dapat pula membuka pori-pori kepala anak.

\section{d. Bersedekah kepada fakir miskin}

Amalan lain yang disyari'atkan adalah bersedekah kepada fakir miskin. Setelah orang tua mencukur rambut anak, ia menimbang hasil cukuran rambut tersebut dan menggantinya dengan emas dan perak atau bisa juga dengan dirham kepada fakir miskin.

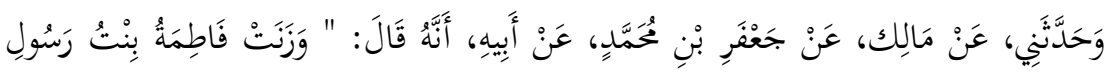

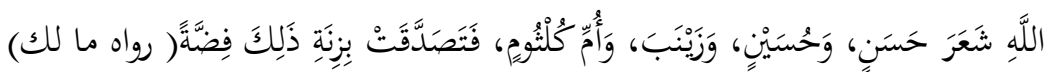

Yahya menyampaikan kepadaku dari Mālik, dari Ja'far ibn Muhammad bahwa bapaknya berkata: "Fatimah R.a pernah

\footnotetext{
${ }^{30}$ Tahnik adalah mengunyahkan kurma dan menggosokkannya ke bagian tenggorokan anak yang baru lahir. Hal itu dilakukan dengan cara menaruh sebagian kurma yang telah dikunyah di atas jari, kemudian dimasukkan jari tersebut ke dalam mulut bayi. Setelah itu, gerakkan jari ke kiri dan ke kanan dengan gerakan yang lembut. Dianjurkan seluruh mulut bayi terkena kurma yang telah dikunyahkan tadi. Apabila tidak didapati kurma, maka boleh mentahnik bayi dengan yang lain yang rasanya manis. Seperti, sari pati gula yang dicampur dengan air bunga sebagai bentuk meneladani Rasulullah Saw. (Abdullah Nasikh Ulwan, Tarbiyatul Aulad fil Islam terj. Arif Rahman Hakim, hlm. 43). 43.

${ }^{31}$ Abdullah Nasikh Ulwan, Tarbiyatul Aulad fil Islam terj. Arif Rahman Hakim, hlm.
} 
menimbang rambut Hasan, Ḥusain, Zainab dan Ummu Kulśum lalu mengeluarkan sedekah perak seberat rambut tersebut”. (H.R Mālik). ${ }^{32}$

\section{e. Memberi wangian dengan minyak za'faran}

Pada rangkaian upacara akikah, orang-orang Jahiliyah biasa mencelupkan kapas pada darah akikah, lalu mengoleskannya pada kepala bayi. Maka Nabi memerintahkan memberi wangian sebagai pengganti (pelumuran) darah tersebut. ${ }^{33}$ Dalam tradisi ini diiringi dengan pembacaan shalawat nabi. Shalawat nabi yang dibaca biasanya adalah shalawat al-barzanji. Pada saat pembacaan shalawat nabi, tepatnya pada saat berdiri (mahalul qiyam) sang bayi digendong oleh sang ayah.

\section{B. Nilai-nilai Pendidikan Islam dalam Hadis Akikah}

\section{Pendidikan Keimanan}

Akikah dapat menghilangkan khurafat (mistik) Jahiliyah. Dan dapat memberikan syafaat (pertolongan) kepada kedua orang tuanya. ${ }^{34}$ Pada zaman Jahiliyah, upacara akikah dilakukan dengan melumuri bayi dengan darah akikah. Hal itu akan berdampak negatif pada si bayi, karena darah merupakan hal najis yang seharusnya dihindarkan. Kemudian Rasulullah Saw menggantinya dengan memberi wangi-wangian.

Pendidikan keimanan juga melalui pemberian do’a kepada anak yang dilakukan dengan mengundang sanak saudara dan tetangga. Dalam upacara tersebut, semua tamu yang hadir ikut serta mendo'akan anak agar kelak menjadi pribadi yang baik.

\footnotetext{
${ }^{32}$ Imam Malik ibn Annas, al-Muwatta' terj. Dwi Surya Atmaja, (Jakarta: Raja Grafindo Persada, 1999), hlm. 264.

${ }^{33}$ Ibnu Hajar al-Aśqalani, Talkhisul Khabir, terj. Amir Hamzah dkk, (Jakarta: Pustaka Azzam, 2012), hlm. 457.

${ }^{34}$ Jamal Abdurrahman, Anak Cerdas Anak Berakhlaq (Metode Pendidikan Anak Menurut Rasul, (Semarang: Pustaka Adnan, 2010), hlm. 27.
} 


\section{Pendidikan Akhlak}

Dari hadis yang diriwayatkan oleh Samurah terdapat kata يُسَمَّىى artinya "memberi nama kepada anak". Nama tersebut merupakan harapan agar anak sepadan atau sederajat dengan manusia pada umumnya. Salah satu syarat diakuinya derajat manusia dengan lainnya karena manusia memiliki sebuah nama. ${ }^{35}$ Pemberian nama yang baik untuk anak akan membuat dirinya merasa dihormati dan dihargai. Dengan seperti itu, anak akan mampu mengembangkan potensi dirinya. Sehingga ia mampu memberikan contoh akhlak mulia dan menjadi figur bagi masyarakat sekitarnya. $^{36}$

Besarnya harapan orang tua melalui nama yang diberikan kepada anak dipengaruhi oleh besar kecintaannya kepada anak. Diharapkan, anak kelak bisa tumbuh dewasa sesuai dengan kandungan makna dalam nama yang diberikan. Selain mengandung harapan, nama juga mengandung unsur do'a yang akan mensupport orang yang mempunyai nama untuk berperilaku sebagaimana kandungan makna dari nama itu. Di sini terdapat unsur agar si anak kelak menjadi anak yang baik (berakhlak mulia, selamat, sehat dan beruntung).

men-tahnik atau memberi yang manis-manis di mulut bayi. Dengan mentahnik diharapkan jika besar nanti anak bertutur kata yang manismanis, berkata-kata yang sopan kepada yang lebih tua, tidak membuat orang tersinggung dan sakit hati jika mendengarnya. Pada saat men-tahnik atau memberi sesuatu yang manis kemulut bayi. Seringkali juga diberi yang manis dan yang asin, maknanya adalah, yang manis itu pada saat dia berkata keluar dari mulutnya selalu mengandung sesuatu disenangi oleh orang lain kemudian jika yang asin setiap perkataannya menjadi berbekas

${ }^{35}$ Abdullah Nasikh Ulwan, Tarbiyatul Aulad fil Islam, terj. Khalilullah Ahmas Masjkur Hakim, hlm. 60.

${ }^{36}$ Abdullah Nasikh Ulwan, Mencintai dan Mendidik Anak secara Islami, (Jogjakarta: Darul Hikmah, 2009), hlm. 154. 
pada setiap orang yang mendengarnya dan perkataanya itu juga berpengaruh.

\section{Pendidikan Kesehatan}

Dalam hadis yang diriwayatkan oleh Samurah terdapat lafadz وَيُحْلَقُ رَأْسُُُ artinya "mencukur rambut kepalanya (anak)". Hal ini merupakan bagian dari upaya memberikan pendidikan kesehatan sejak dini kepada anak. Di mana mencukur rambut kepala anak yang baru dilahirkan dapat menguatkan kepala anak dan membuka pori-porinya. Selain itu, dengan mencukur rambut kepala akan memperkuat tubuh anak, membuka selaput kulit kepala dan mempertajam indera penglihatan, penciuman dan pendengaran. $^{37}$ Dengan mencukur rambut anak, kotoran-kotoran yang terbawa dari dalam rahim dan menempel pada rambut akan hilang, dan akan dapat dihindari berkembangnya banyak mikro organisme yang dapat menimbulkan penyakit dan mengelupaskan kulit. ${ }^{38}$

\section{Pendidikan Sosial}

Akikah di dalamnya terdapat proses mencukur rambut kepala anak yang kemudian rambut hasil cukuran tersebut dikumpulkan lalu ditimbang, beratnya disamakan dengan berat perak dan nilai tukar perak tersebut ditukarkan dengan nilai rupiah lalu disedekahkan. Hal ini mengandung pendidikan sosial yang dapat mengurangi kemiskinan dan mewujudkan suasana saling menolong, saling menyayangi, dan saling menjamin dalam kelompok masyarakat. ${ }^{39}$ Hal tersebut akan memperkuat silaturrahim antara masyarakat. Maksud dari mempererat silaturrahim yaitu menguatkan ikatan keakraban dan kecintaan antara sesama anggota masyarakat karena

\footnotetext{
${ }^{37}$ Abdullah Nasikh Ulwan, Tarbiyatul Aulad fil Islam, terj. Khalilullah Ahmas Masjkur Hakim, hlm. 56.

${ }^{38}$ Syafiarrahman, Abu Hadian, Hak-hak Anak dalam Syari'at Islam (dari Janin hingga Pasca Kelahiran), (Yogyakarta: Manar, 2003), hlm. 86.

${ }^{39}$ Abdullah Nasikh Ulwan, Tarbiyatul Aulad fil Islam, terj. Khalilullah Ahmas Masjkur Hakim, hlm. 56.
} 
berkumpulnya mereka di hadapan hidangan yang sudah disediakan artinya bergembira dalam menyambut anak yang baru lahir.

\section{Pendidikan Psikologi}

Di antara prinsip-prinsip pendidikan yang diletakkan Islam dalam mendidik anak adalah menyandarkan nama anak kepada nama ayahnya. Penyandaran ini mempunyai efek psikologis yang luhur dan manfaat besar, antara lain:

a. Menumbuhkan perasaan dimuliakan dan dihormati pada jiwa anak.

b. Menumbuhkan kepribadian sosial karena menumbuhkan perasaan punya martabat kebesaran dan dihormati.

c. Melembutkan dan memasukkan kegembiraan kepada anak dengan penyandaran yang dicintainya. ${ }^{40}$

Nama tidak hanya terpakai semasa hidup di dunia, tetapi sampai di akhirat kelak. Di dalam hisab anak akan dipanggil dengan namanya sewaktu di dunia. Oleh karena itu, hendaknya para orang tua memberi nama yang baik dan indah kepada anaknya.

\section{Pendidikan Keindahan}

Dalam hadis Samurah dianjurkan untuk mencukur rambut anak. Cara mencukur rambut yang dilarang adalah mencukur secara Qoza ${ }^{41}$ sebagaimana dijelaskan dalam hadis yang diriwayatkan oleh Ibnu 'Umar:

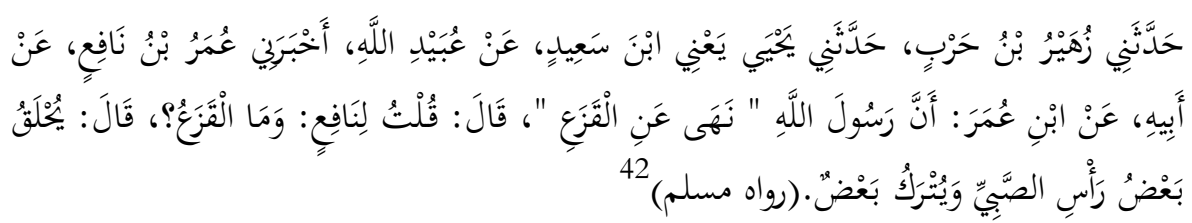

${ }^{40}$ Abdullah Nasikh Ulwan, Tarbiyatul Aulad fil Islam, hlm. 51.

${ }^{41}$ Pengertian Qoza' adalah pertama; mencukur kuncung. Kedua; mencukur bagian yang tengah saja. Ketiga; mencukur yang pinggir dan meninggalkan yang tengah. Keempat; mencukur bagian depan dan meninggalkan bagian belakang. Lihat. Miftahul Huda, Idealitas Pendidikan Anak (Tafsir Tematik Q.S Lukman), (Malang: UIN-Malang Press, 2009), hlm. 66.

${ }^{42}$ Imam Nawawi, Manhaj Syarhu Șahih Muslim, terj. Fațoni Muhammad, (Jakarta: Darus Sunah Prees, 2011), hlm. 198. 
Zuhair bin Harb telah menceritakan kepadaku, Yahya yakni ibnu Sa'īd telah menceritakan kepadaku, dari 'Ubaidillah, 'Umar bin Nafi' telah menceritakan kepadaku dari bapaknya dari Ibnu 'Umar ra. Bahwasanya Rasulullah SAW melarang melakukan qaza', dia 'Umar berkata: "aku bertanya kepada Nafi' apa itu qaza'?" Dia menjawab "Seseorang yang memotong sebagian rambut kepalanya dan menghilangkannya." (H.R Muslim).

Seperti dinyatakan Ibnu Qayyim, termasuk kesempurnaan mencintai Allah dan Rasul-Nya adalah bersikap adil. Rasulullah memerintahkan berbuat adil sampai kepada masalah pribadi seseorang, maka beliau pun melarang mencukur sebagian rambut kepala dan membiarkan sebagian lainnya karena perbuatan itu termasuk perbuatan aniaya kepada kepala, sebagian gondrong dan sebagian gundul. ${ }^{43}$

Rasulullah sangat memperhatikan agar seorang Muslim tampil di masyarakat dengan cara yang layak. Mencukur sebagian rambut kepala dan membiarkan sebagian lainnya akan mengurangi kehebatan dan keindahan dirinya, selanjutnya akan mengurangi kepribadian Islam yang menjadi ciri pembeda seorang Muslim dari pada pemeluk agama dan keyakinan lain, bahkan dari seorang fasik, dan yang moralnya rusak.

\section{PENUTUP}

Akikah ialah binatang yang disembelih untuk keselamatan anak yang baru lahir pada hari ketujuh. Dalam tradisi akikah terdapat serangkaian ritual di antaranya: diberi nama pada hari ke tujuh, memberikan doa, mencukur rambutnya dan bersedekah senilai berat rambut, dan memberi wangi-wangian. Akikah mengandung nilai-nilai pendidikan yang dapat digunakan orang tua sebagai dasar dalam proses mendidik anak sejak lahir serta sebagai pembuka syafa'at bagi orang tua sehingga kesejatian hubungan batin antara anak dan orang tua dapat terjalin, sedangkan bagi orang tua adalah sebagai rasa syukur atas karunia yang telah dianugerahkan kepadanya yaitu anak.

\footnotetext{
${ }^{43}$ Ibnu Qayyim, Tuhfatul Maudud Jami'u al-Huquq Mahfudoh, (Beirut: Darul Kitab al-‘Azzi, 1997), hlm. 101.
} 
Di antara nilai-nilai pendidikan Islam yang terdapat dalam ritual-ritual akikah di antaranya: pendidikan keimanan, pendidikan akhlak, pendidikan kesehatan, pendidikan sosial, pendidikan ekonomi, pendidikan psikologi dan pendidikan keindahan. Dengan mengakikahi anak yang baru lahir, bisa memberikan pengaruh pertumbuhan dan perkembangan anak baik secara jasmaniah maupun rohaniah sehingga kelak menjadi anak yang shaleh dan berbakti kepada kedua orang tuanya serta mereka dapat hidup bahagia, baik di dunia maupun di akhirat. 


\section{DAFTAR PUSTAKA}

A.J Wensinck, Mu'jam al-Mufahras li al-fadz Hadis an-Nabawy, Madinah: Baril, 1962.

Abdul Qadir Syaibah al-Hamd, Syarah Buluqul Maram, terj. Muhammad Iqbal dkk, Jakarta: Darul Haq, 2014.

Abdurrahman, Jamal, Anak Cerdas Anak Berakhlaq (Metode Pendidikan Anak Menurut Rasul, Semarang: Pustaka Adnan, 2010.

al-Hauti, Kamal Yusuf, Al-Jami al-Sahih Sunan Al-Turmudzi) Juz IV, Beirut: Dar al-Kutub al-Ilmiah, t.t.

Arief, Armai, Pengantar Ilmu dan Metodologi Pendidikan Islam, Jakarta: Ciputat Pers, 2002.

Darajat, Zakiyah dkk, Ilmu Pendidikan Islam, Jakarta: Bumi Aksara, 2014.

Daulay, Haidar Putra, Pemberdayaan Pendidikan Islam di Indonesia, Jakarta: Rineka Cipta, 2009.

Dib al-Buga, Musțafa, al-Tażib fi Adillati Matn al-Ghayah wa al-Taqrib, terj. Toto Edidarmo, Jakarta: Mizan Publika, 2012.

Fihris, Ilmu Pendidikan Islam, Semarang: CV. Karya Abadi Jaya, 2015.

Fitrianor, Muhammad, "Nilai-Nilai Pendidikan Islam Dalam Pelaksanaan Akikah dan Tasmiah Di Kel.Baamang Hulu Kec.Baamang Kab.Kotim", Jurnal Studi Agama dan Masyarakat, Volume 11, Nomor 1, Juni 2015

Hanan Ațiyah Aț-Ṭuri, Mendidik Anak Perempuan di Masa KanakKanak,(Ad-Daur At-Tarbawy Li Al-Walidain fi Tansyi'ah Al-Fatah Al-Muslimah fi Marhalah At- Tufulah), terj. Aan Wahyudin, Jakarta: Amzah, 2007.

Huda, Miftahul, Idealitas Pendidikan Anak (Tafsir Tematik Q.S Lukman), Malang: UIN-Malang Press, 2009.

Ibnu Hajar al-Asqalani, Talkhisul Habir, terj. Amir Hamzah dkk, Jakarta: ustaka Azzam, 2012.

Ibnu Hajar al-Aśqalani, Talkhisul Khabir, terj. Amir Hamzah dkk, Jakarta: Pustaka Azzam, 2012. 
Ibnu Qayyim, Tuhfatul Maudud Jami’u al-Huquq Mahfuḍoh, Beirut: Darul Kitab al-'Azzi, 1997.

Ilmiyyah, Nafilatul, "Pemahaman Dan Implementasi Hadits-Hadits Aqiqah Pada Masyarakat Desa Kauman Kota Kudus", Skripsi, UIN Walisongo: 2016.

Imam Abi Abdillah bin Ismail bin Ibrahim Ibn Mugirah al-Bukhari al-Ju'fi, Shahih al-Bukhari Juz V.

Imam Malik ibn Annas, al-Muwatța' terj. Dwi Surya Atmaja, Jakarta: Raja Grafindo Persada, 1999.

Minarti, Sri, Ilmu Pendidikan Islam, Jakarta: AMZAH, 2013.

Mujib, Abdul dan Jusuf Mudzakkir, Ilmu Pendidikan Islam, Jakarta: Kencana Prenada, 2006.

Mukhtar, Heri Jauhari, Fiqh Pendidikan, Bandung: PT Remaja Rosdakarya, 2005.

Nawawi, Imam, Manhaj Syarhu Șahih Muslim, terj. Fațoni Muhammad, Jakarta: Darus Sunah Prees, 2011.

Sabiq, Sayyid, Fiqh as-Sunah, terj. Noor Hasanuddin, Jakarta: Darul Fath, 2004.

Sulaiman Abi Daud, Sunan Abi Dawūd, Beirut: Darul Kitab al-'Ilmiah, 1996.

Syafiarrahman, Abu Hadian, Hak-hak Anak dalam Syari'at Islam (dari Janin hingga Pasca Kelahiran), Yogyakarta: Manar, 2003.

Syukur, Fatah, Sejarah Pendidikan Islam, Semarang, Pustaka Rizki Putra, 2012.

Uhbiyati, Nur, Ilmu Pendidikan Islam, Bandung: Pustaka Setia, 1997.

Ulama'i, Hasan Asy'ari, Aqiqah dengan Burung Pipit, Semarang: Rasail Media Group, 2012.

Ulwan, Abdullah Nasikh, Mencintai dan Mendidik Anak secara Islami, Jogjakarta: Darul Hikmah, 2009.

------, Tarbiyatul Aulad fil Islam terj. Arif Rahman Hakim, Solo: Insan Kamil, 2016.

Umar, Bukhari, Hadis Tarbawi Pendidikan dalam Perspektif Hadis, Jakarta: Amzah, 2012.

------, Ilmu Pendidikan Islam, Jakarta: AMZAH, 2010. 
Wahbah al-Zuhaili, Fiqih Islam wa Adillatuhu, terj. Abdul Hayyie al-Kattani dkk, Jakarta: Gema Insani, 2011. 